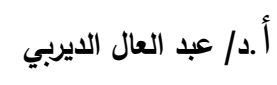

فاطمة صلاح الجندي
السياسة الخارجية الأمريكية إزاء الملف النووي الإيراني

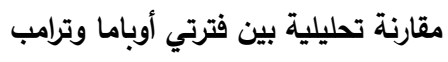

\title{
السياسة الخارجية الأمريكية إزاء الملف النووي الإيراني مقارنة تحليلية بين فترتي أوباما وترامب المباء

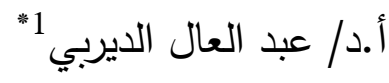

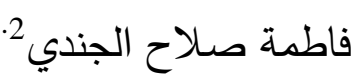 \\ الملخص
}

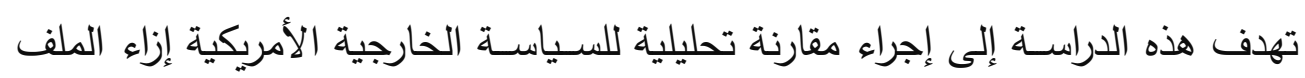

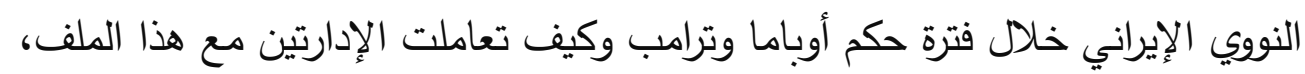

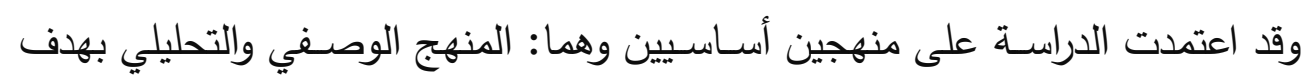

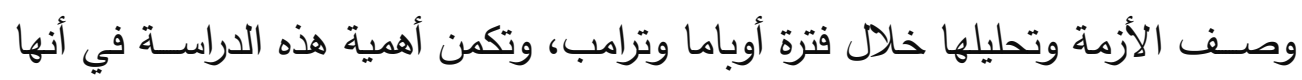
تتناول تغير السياسـة الخارجية الأمريكية تجاه الملف النووي الإيراني خلال فترة أوباما وترامب والذي بدوره قد أثر على تطور البرنامج ودور إيران في منطقة الشرق الأوسط.

1* أستاذ العلوم السياسية المساعد بكلية السياسة والاقتصاد- جامعة السويس

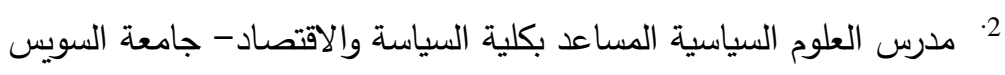




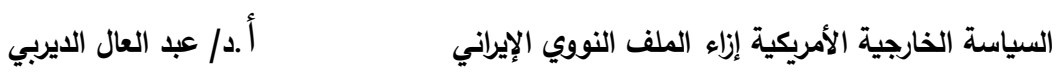

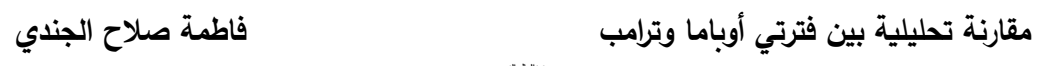

وقد خلصت الدراسة إلى إن السياسة الأمريكية تجاه البرنامج النووي الإيراني لا تختلف

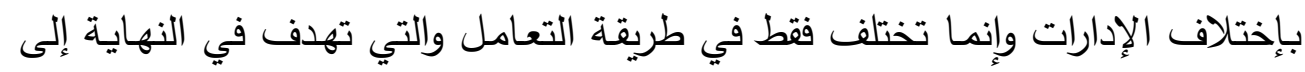
حماية المصالح الأمريكية وعدم ظهور قوة إقليمية تقف أمام أهدافها في المنطقة.

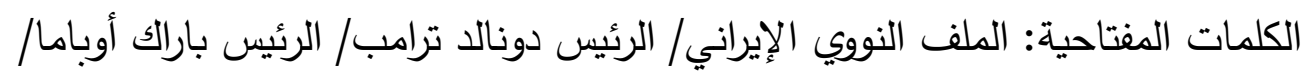
السياسة الخارجية الأمريكية.

Abstract

This study aims to conduct an analytical comparison of US foreign policy regarding the Iranian nuclear file during the Obama and Trump era and how the two administrations dealt with this file.

The study relied on two basic approaches, the descriptive and analytical approach to describe and analyze the crisis during the Obama and Trump period, 


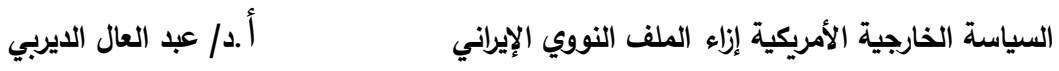

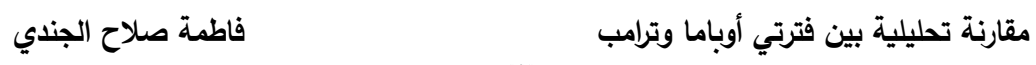

and the importance of this study lies In it deals with the change of US foreign policy towards the Iranian nuclear file during the Obama and Trump period, which in turn affected the development of the program and Iran's role in the Middle East region.

The study concluded that the US policy towards the Iranian nuclear program does not differ according to different administrations, rather it differs only in the way it is dealt with, and ultimately aims to protect American interests and not to see a regional power standing in front of its goals in the region.

Key words: Iran's nuclear file / President Donald Trump / President Barack Obama / US foreign policy. 


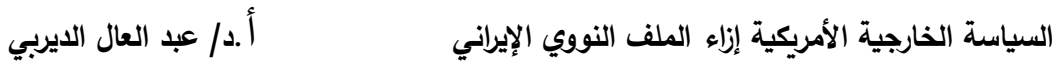

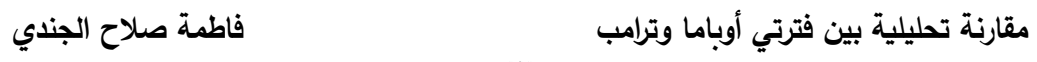

المقدمة

اعتمدت الولايات المتحدة الأمريكية على إيران كقوة إقليمية في منطقة الثـرق الأوسـط

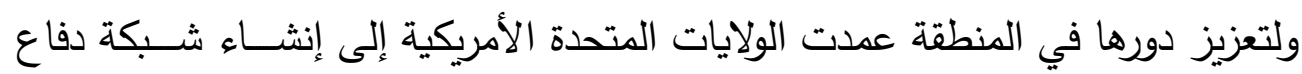

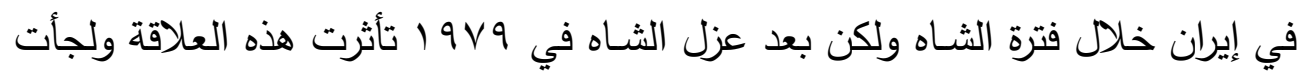
الولايات المتحدة الأمريكية إلى أساليب متثددة في تعاملها مع الحكومة الجديدة.

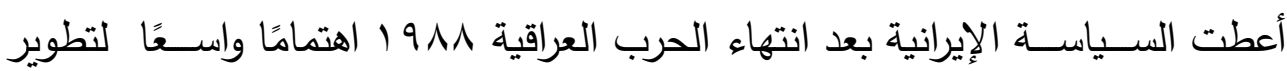

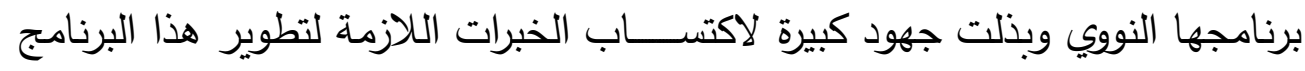

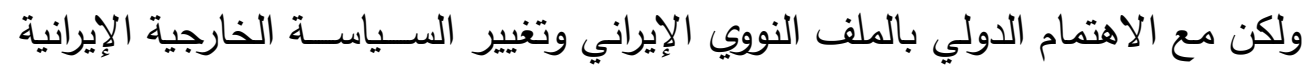

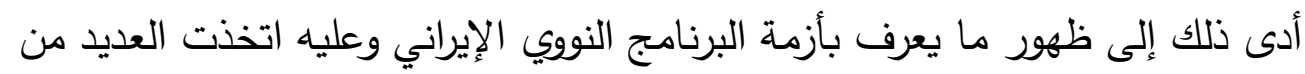

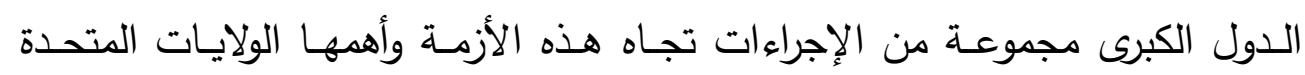

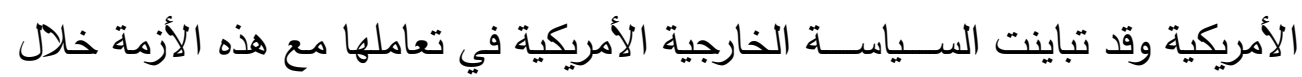

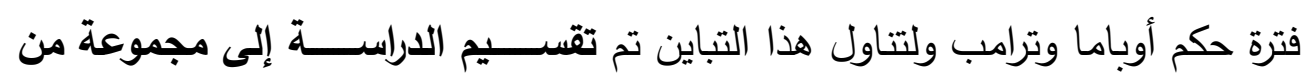
المحاور كالتالي؛ المحور الأول: نشأة البرنامج النووي 


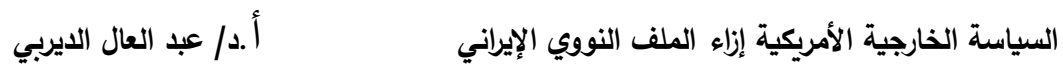

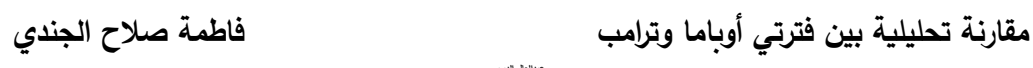

المحور الثاني: السياسة الخارجية الأمريكية تجاه إيران خلال فترة أوباما

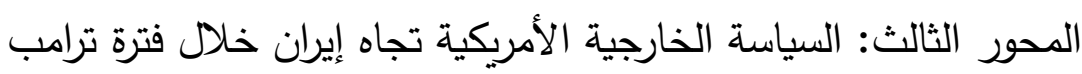

\section{المحور الأول نشأة البرنامج النووي الإيراني}

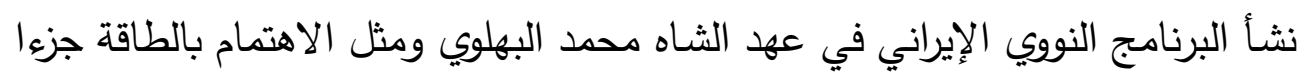

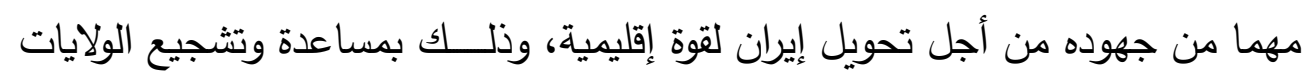

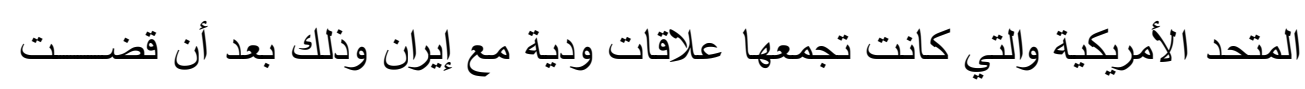
الاســـخبارات الأمريكية بمســـاعدة الاســـخبارات البريطانية على ثورة رئيس الوزراء

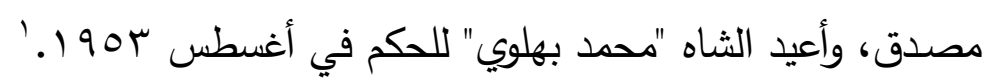

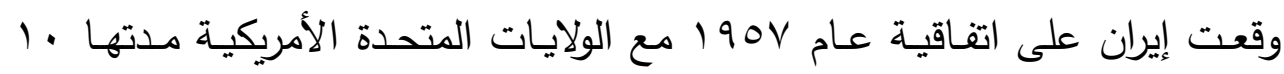

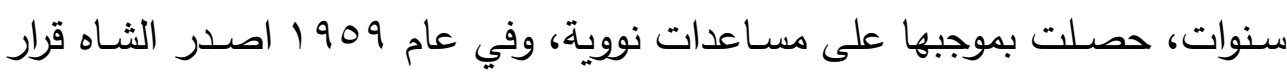

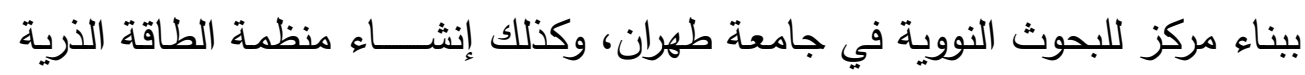

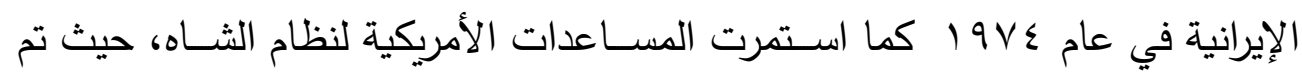

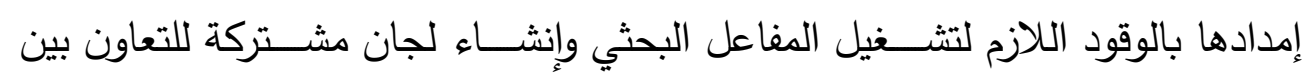




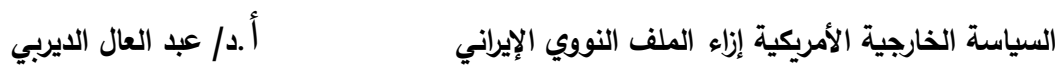

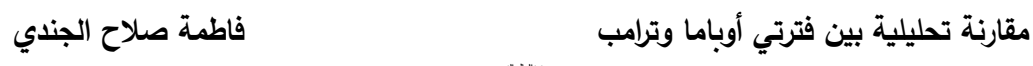

البلدين. وفي عام $19 V V$ وقعت الولايات المتحدة الأمريكية وإيران اتفاقية لتبادل التقنية

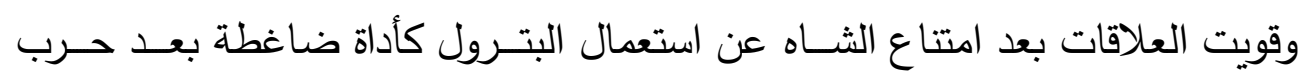

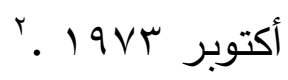

عقدت إيران اتفاقيات أخرى حيث عقدت مع فرنسا في عـام 9 أتفاقية للاستفادة

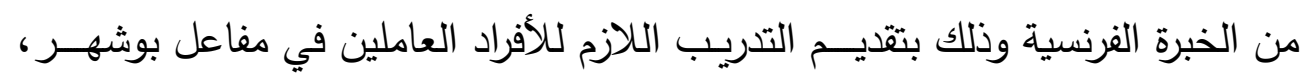
وعقدت اتفاقية في 19VV لإنشاء مفاعل

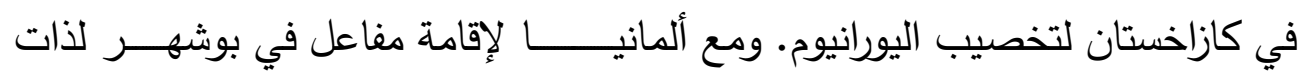

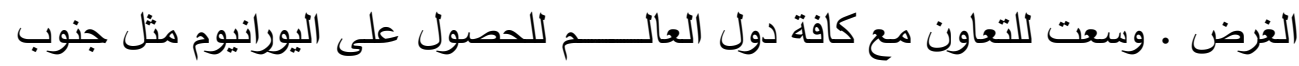
أفريقيا و الدنمارك والأرجنتين والهند وأستراليا. 


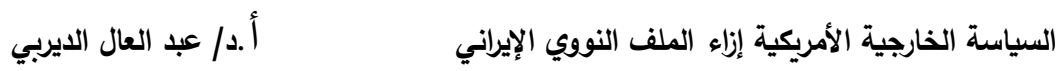

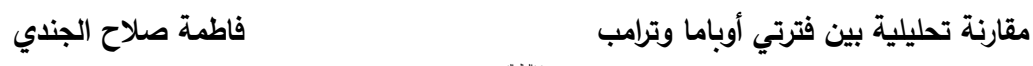

وانضمت إلى اتفاقية عدم انتشار الأسلحة النووية وذلك عام 1941 والتي دخلت حيز

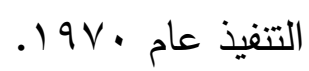

من خلال ما تم تقديمه يمكن القول أن إيران كانت تسعى ظاهريًا إلى الحد من انتشار

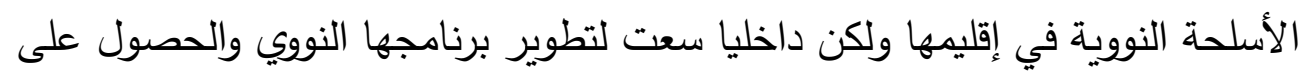
التقنيات الحديثة وبناء مراكز عديدة خاصة بالبحوث النون النووية.

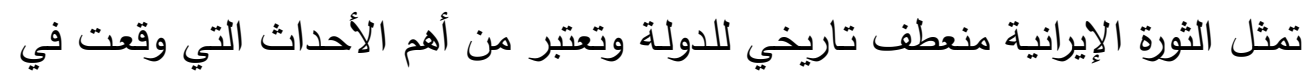

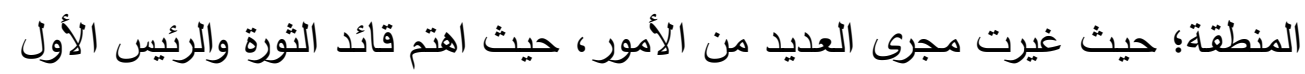

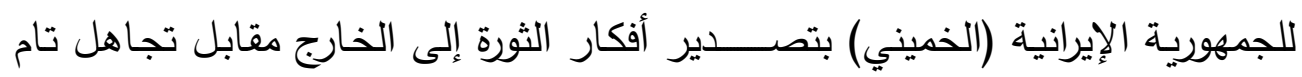

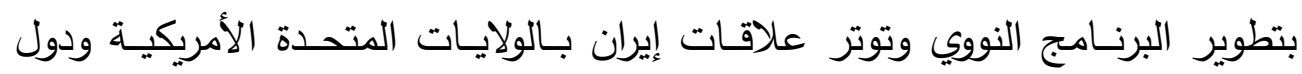
أوروبا. لكن سرعان ما غير قادة إيران نظرتهم وذلك بعد القصف الذي تعرضت إليه المنشآت

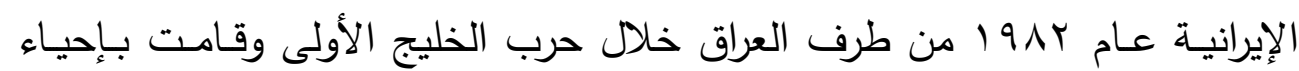

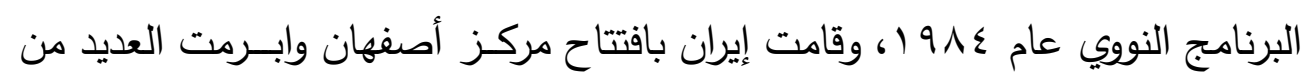

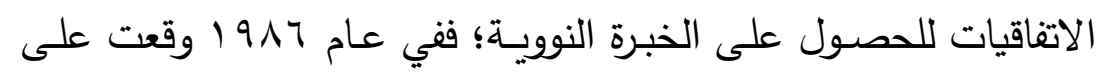




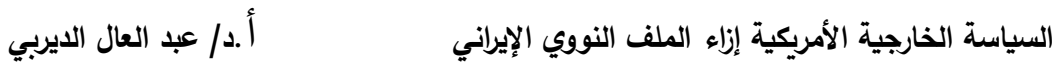

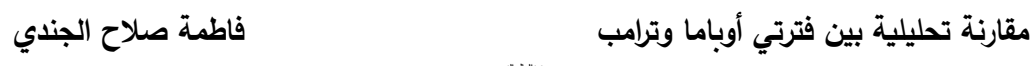

اتفاقية مـع باكستـان لتدريب العلمـاء الإيرانيين، وفي عـام 9 1 ا وقعت على اتفاقية مـع الأرجنتيـن للحصــول على اليورانيـوم المخصــب والوقود النووي وتجديد بعض الاتفاقيات للحصول على اليورانيوم

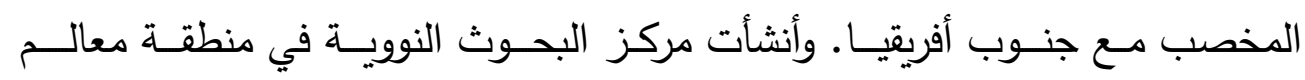

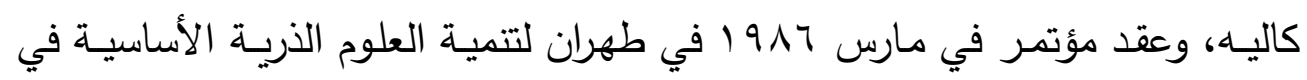
إيران. كان الهدف المعلن في هذه المرحلة هو اســـتخدام المفاعلات النوويـة لإنتاج الطاقة الكهربائية ولكن مع بداية التســـعينات دخل البرنامج النووي الإيراني مرحلة جديدة مع فع فـ

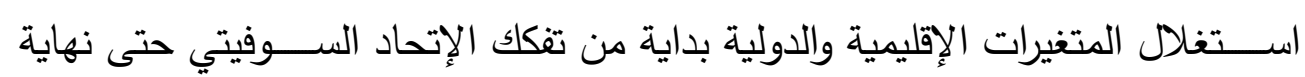
حرب الخليج الثانية. وحاولت إيران الاسـتفادة من خبرات باكسـتان وكوريا الثـمالية، وتلاها ظهور التعاون

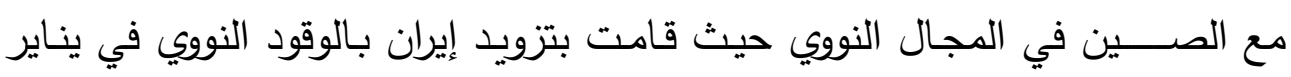




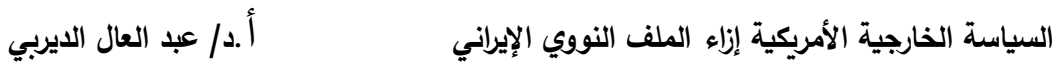

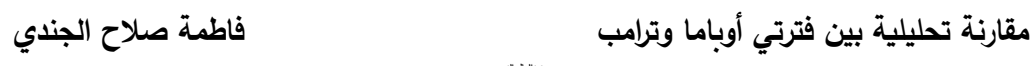

1991، ووقعت اتفاقية التعاون في ميدان الطاقة النووية مع روســيا عام ب9919 لاستكمال مفاعل بوشـهر بطاقة ألف ميجاوات. وعقدت اتفاقية مع الصـين تمكن إيران من إنتاج أسلحة نووية بصورة تدريجية . أمســام تضاعف النشاط البحثي النووي الإيراني برزت ضغوط ورفض أمريكي ووجهت الدول الأوروبية اتهاما لإيران بأن المخزون النفطي لا يستدعي إنشـاء هذه المفاعلات

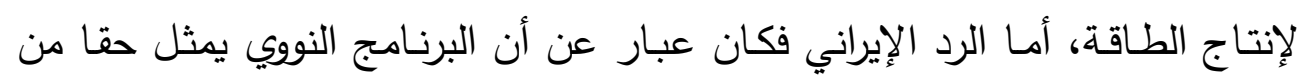
حقوقها في اسـتخدام الطاقة لتثـغيل محطات الطاقة الكهربائية في الإطار الســلمي. وحاولت الولايات المتحدة الأمريكية عرقلة البرنامج النووي الإيراني حيث قامت بالتهديد بفرض عقوبات اقتصـــادية في عام الو 99 على كل الدول التي تتعاون مع إيران في المجال النووي. وفي عام ب99 1 في أعقاب انتصارها في حرب الخليج الثانية أصدرت قانونا بمنع تصدير أي معـــدات نووية إليران والعراق، ثم أصدرت قانون عام 1990 يفرض عقوبات على أي شركة تستثر في تطوير صناعة النفط في 


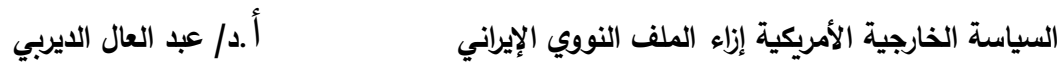

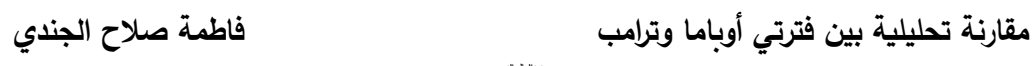

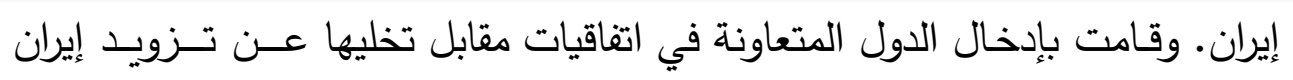

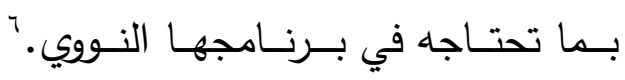

\section{المحور الثاني}

\section{السياسة الخارجية الأمريكية تجاه إيران خلال فترة أوباما}

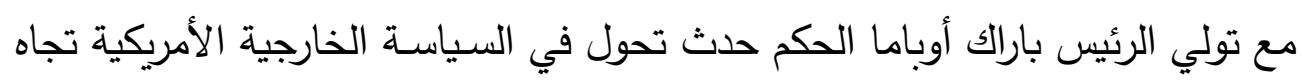

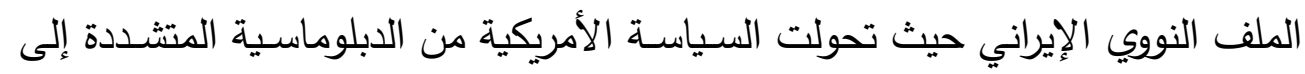

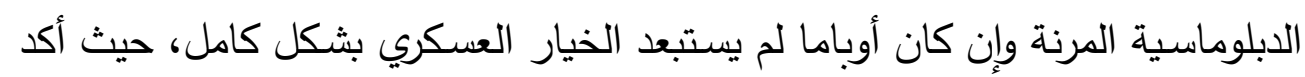

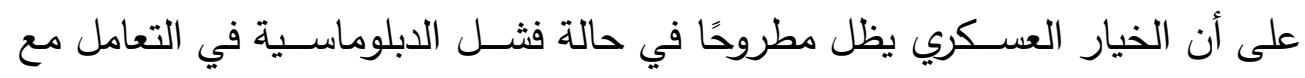

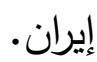
وفي مارس 9 . . ب وخلال أعياد النيروز (رأس الســنة الفارسـية) مدح الرئيس أوباما

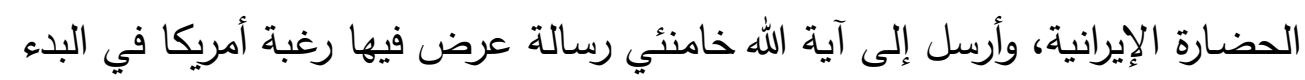

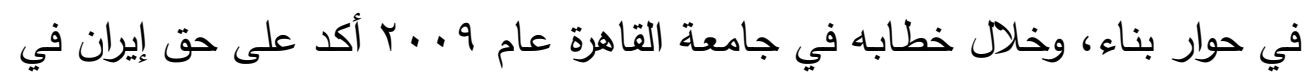




$$
\begin{aligned}
& \text { السياسة الخارجية الأمريكية إزاء الملف النووي الإيراني أدم/ عبد العال الديربي }
\end{aligned}
$$

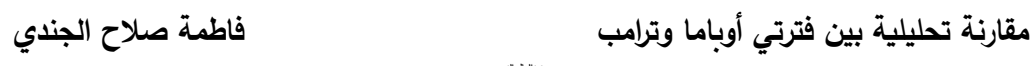

امتلاك الطاقة النووية السلمية وذلك في إطار معاهدة عدم الانتشار النووي، وأكد على اسـتعداده لإجراء مباحثات غير مشــروطة مع إيران كما أكد الرئيس الإيراني أحمدي نجاد استعداد إيران لمفاوضات وفق مبدأ الاحترام المتبادل. v

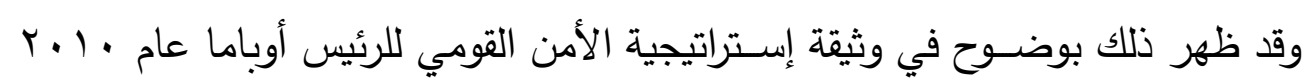

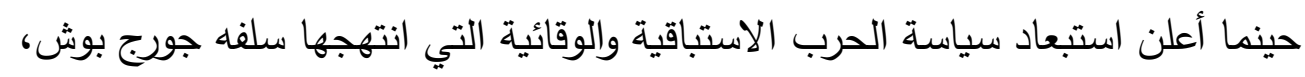

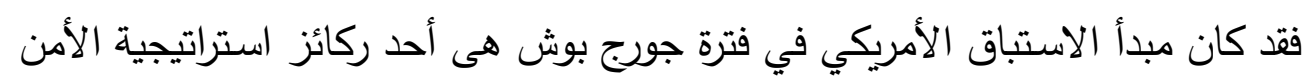
القومي فقد طرح هذا المبدأ بعد حرب أفغانستان وتم تطبيقه

عميًا في حرب العراق عام r . . r ، والتي قامت بها الولايات المتحدة انفراديًا مما أصبخ مبدأ بوش بطابع هجومي.

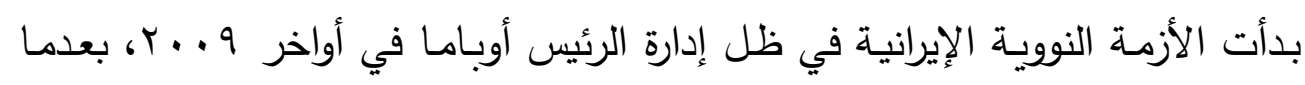

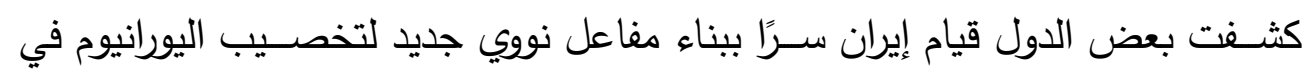
مدينة “ق” دون علم الوكالة الدولية للطاقة الذرية؛ وهو ما يعد مخالفة من جانب إيران لالتزاماتها الدولية في هذا الثأن. ^ 


$$
\begin{aligned}
& \text { السياسة الخارجية الأمريكية إزاء الملف النووي الإيراني أدم/ عبد العال الديربي }
\end{aligned}
$$

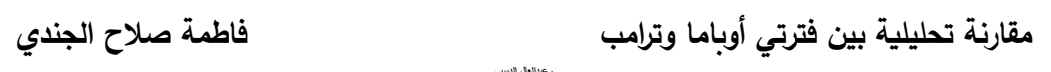

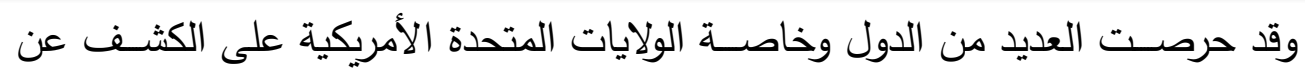

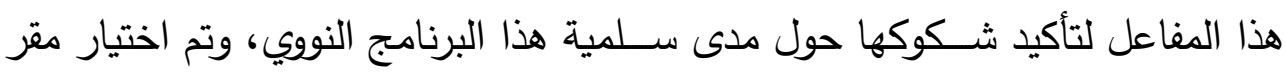

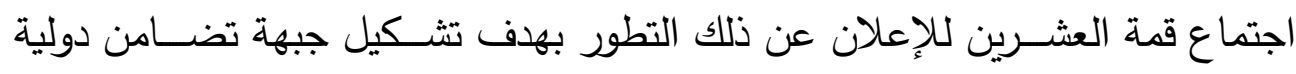

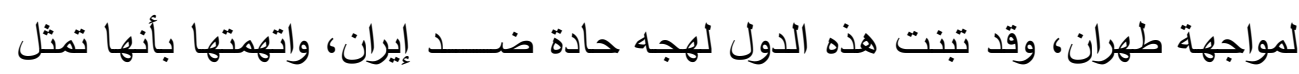

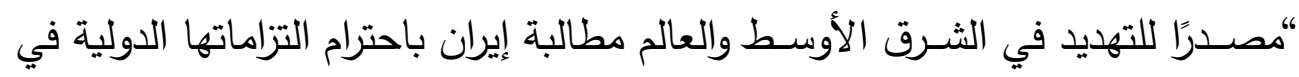
هذا الثأن. ولامتصــاص غضــب المجتمع الدولي عمدت إيران إلى اتخاذ خطوات تكتيكية مكنتها

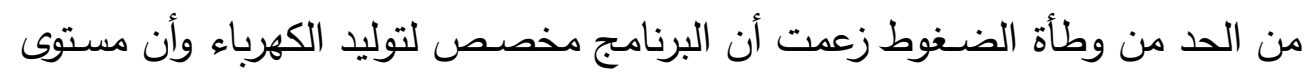

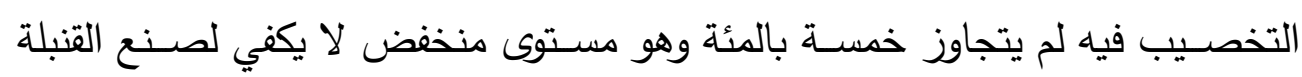

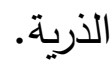

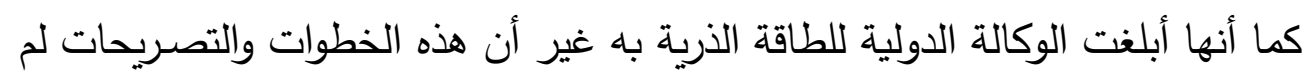

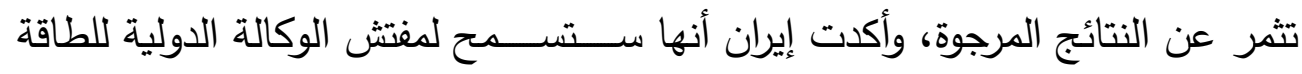

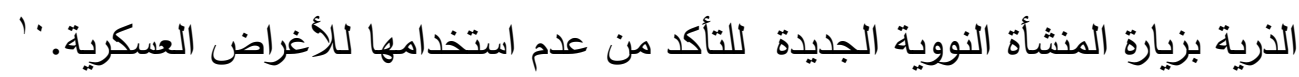




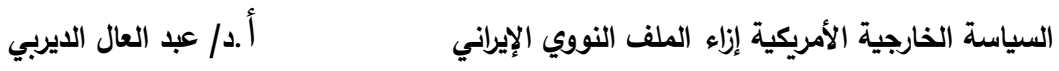

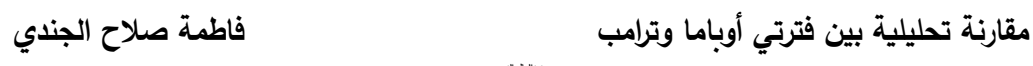

وأجريت محادثات ثنائية مع الولايات المتحدة الأمريكية، ووافقت إيران على إرســـال

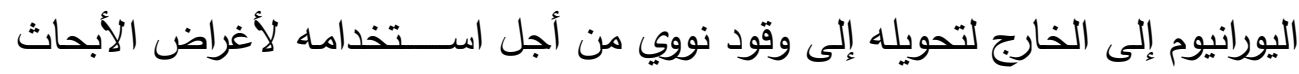

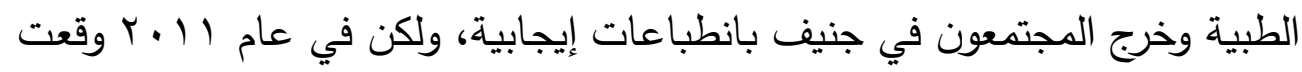
عدة تطورات دفعت الملف النووي الإيراني بقوة إلى قمة القضايا وحفلت وسائل الإعلام

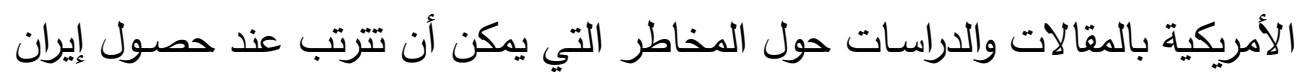

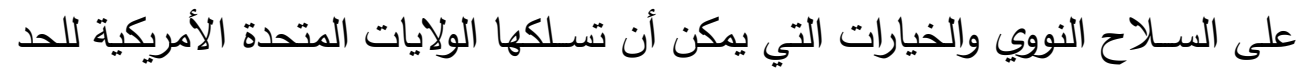

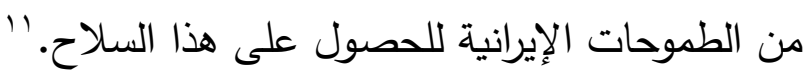
ومن أبرز التطورات التي زادت من حدة توتر الأجواء المحيطة بالملف النووي الإيراني

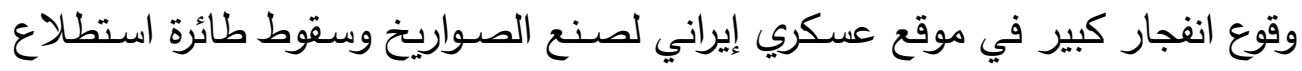
أمريكية بدون طيار تستعملها وكالة المخابرات المركزية من أجل التجسـ علي على إيران داخل الأراضي الإيرانية.

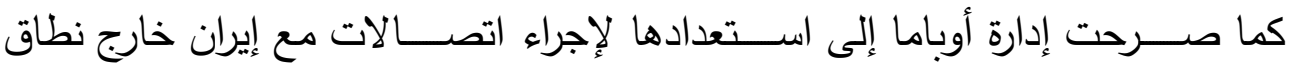

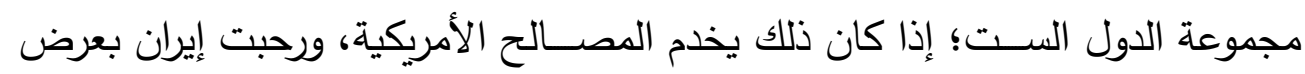

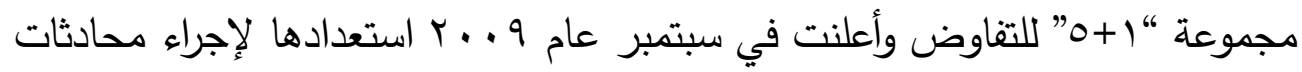




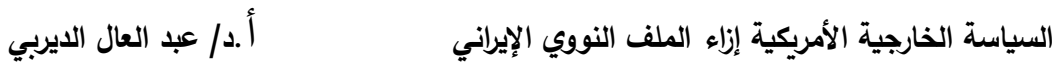

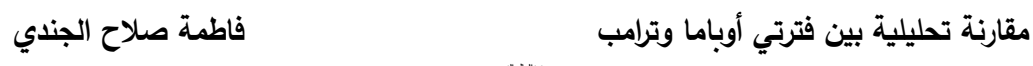

تتتاول كل القضـايا الأمنية التي تسـبب قلقًا للغرب بثـرط ألا تتناول تخصـيب إيران

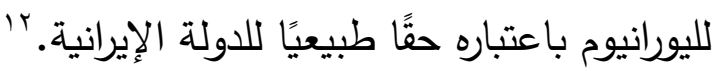

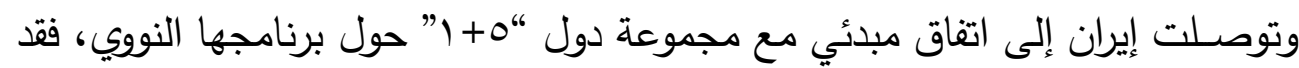

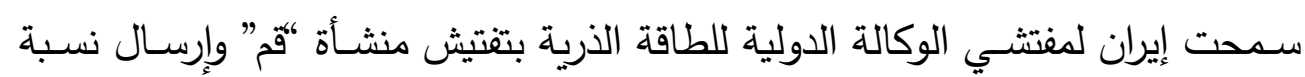
من اليورانيوم المخصب الإيراني إلى الخارج واستيراده بعد أن يتم تحويله إلى وقود.

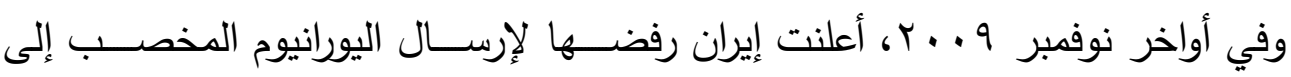

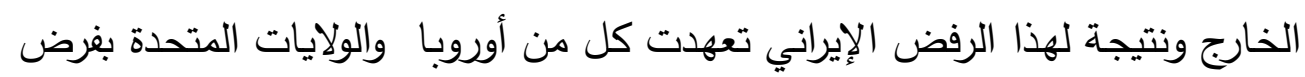
عقوبات أشد وأقوى ضد إيران.

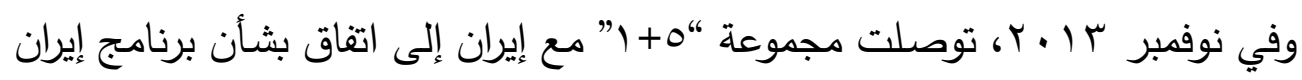

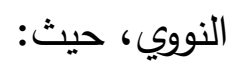

تتعهد إيران بتخفيض عمليات تخصـيب اليورانيوم بنسـبة ه\%؛ وذلك مقابل رفع بعض العقوبات تدريجيًا واستمرار المفاوضات. تجنب إصدار أي عقوبات جديدة ضد إيران. 


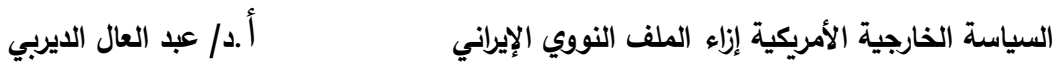

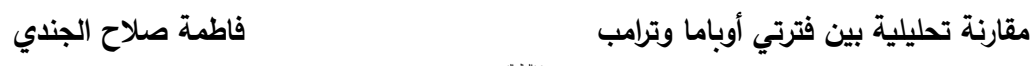

الحرص على عدم وصول نسبة صادرات نفط إيران إلى ما هو أقل من النسبة

$$
\text { الحالية. }
$$

رفع الحظر على شراء وبيع الذهب والمعادن الثينة.

• رفع الحظر المفروض على صـناعة السيارات وكذلك المنتجات البتروكيميائية

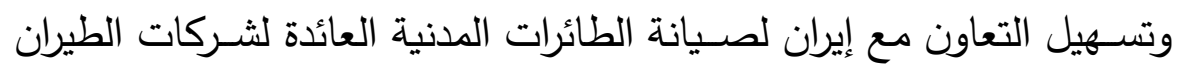

$$
\text { الإيرانية }
$$

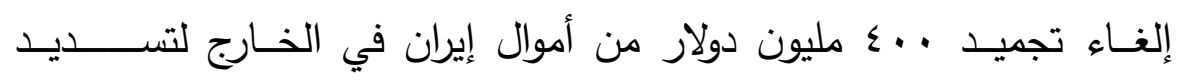
تكاليف دراسة الطلبة الإيرانيين المبتعثين إلى الخارج والتعاون مع إيران لثراء المواد الغذائية والطبية.

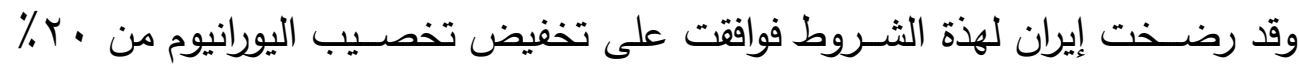

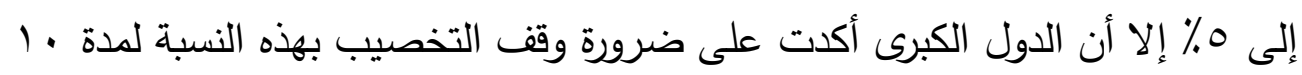
سنوات وهو ما رفضته إيران. وانتهت المفاوضات بالفشل في التوصل إلى اتفاق بسبب إصرار فرنسا للحصول على

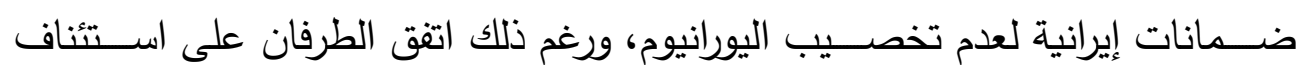

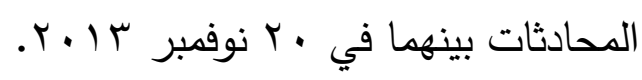




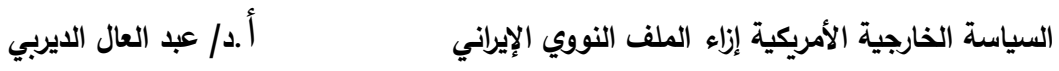

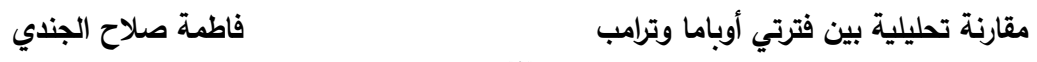

في نهاية r| • ب نجحت إيران ومجموعة دول “ه+|" في عقد اتفاق بجنيف حددته بـ ج أشـهر قابلة للتمديد، يقضــي بأن تحد إيران من نشـاطها النووي مقابل رفع محدود

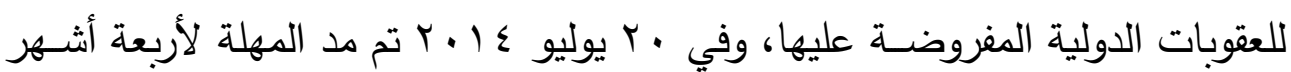

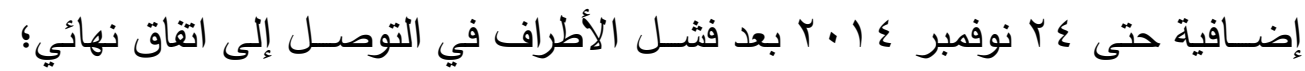
وذلك لإتاحة مزيد من الوقت للدول الســتة وإيران للتوصــل إلى اتفاق نهائي شــامل يضـــن الطبيعة السـلمية للبرنامج النووي الإيراني في مقابل رفع العقوبات التي أثرت على الاقتصاد الإيراني لعده سنوات وبعد أيام من مفاوضات مكثفة تم الاتفاق على مد الإيري

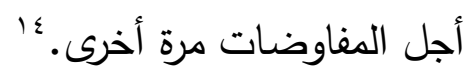

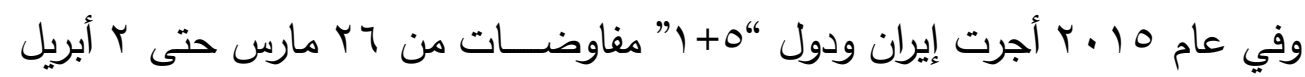

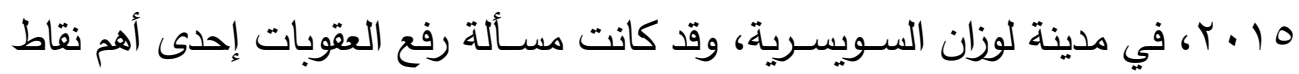
الخلاف، ففي حين أرادت إيران أن ترفع العقوبـات فور التوقيع على الاتفاق النهائي فإن الولايات المتحدة وبـاقي الدول أصـــروا أن يكون رفع العقوبـات مرتبطًا بـخول الاتفاق حيز التنفيذ وتصديق الوكالة الدولية للطاقة الذرية. 


$$
\begin{aligned}
& \text { السياسة الخارجية الأمريكية إزاء الملف النووي الإيراني أدم/ عبد العال الديربي }
\end{aligned}
$$

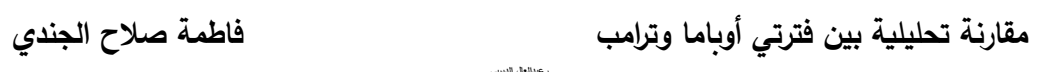

\section{المحور الثالث}

\section{السياسة الخارجية الأمريكية تجاه إيران خلال فترة ترامب}

أعلن رئيس الولايـات المتحدة دونـالـد ترامـب في مـايو عـام ^ ا ـ ب خروج بلاده من

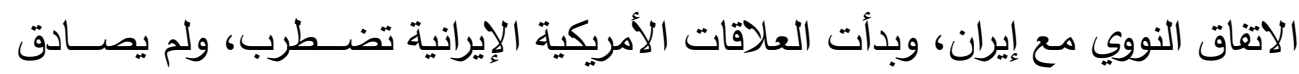
دونـالـــ ترامـب على التزام إيران ببنود الاتفـاق النووي، إذ إن كـل رئيس ملزم من الكونجرس بأن يصادق كل و يومًا ما إذا كانت إيران ملتزمة ببنود

الاتفاق، وأن الاتفاق لا زال يصــب في مصــلحة البلد أم لا. أعطي ترامب . ب يومًا

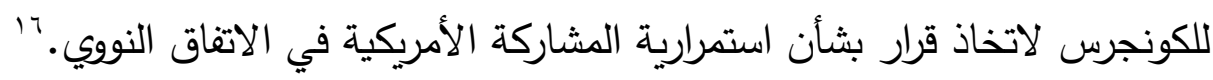

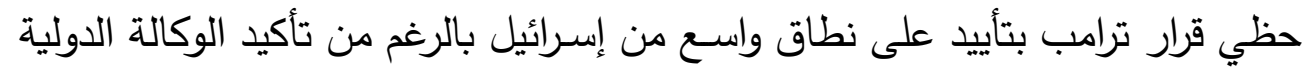

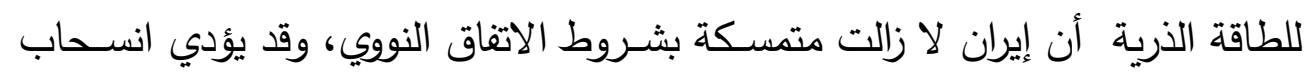

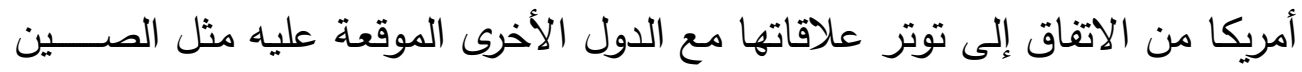
وألمانيا، والتي قد ترفض فرض أي عقوبات على على طهران في حال تراجعت واشنطن. 


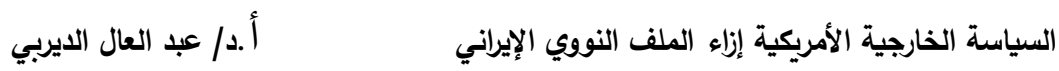

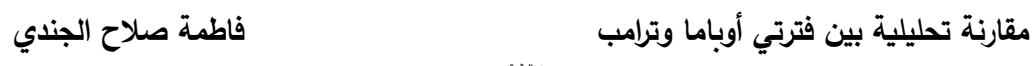

وتهدف اســتراتيجية الرئيس الأمريكي ترامب في تعامله مع الملف النووي الإيراني إلى

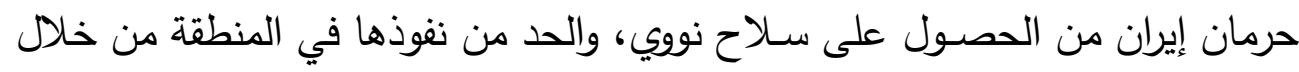
تعزيز العلاقات مع الحلفاء التقليديين للولايات المتحدة. أن انسحاب الرئيس الأمريكي ترامب من الاتفاق الثامل لتسوية قضية البرنامج النووي

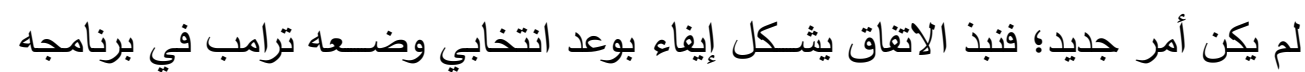
الانتخابي. وقد ثارت تسـاؤلات داخل الولايات المتحدة والثـركاء الأوروبيين الموقعين على الاتفاق

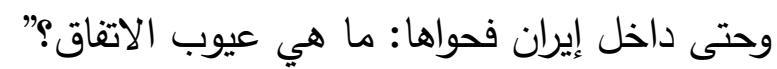

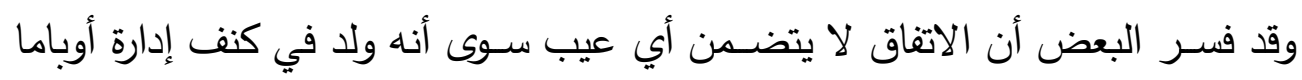
وانه يحاول إلغاء أي إنجاز حققه سلفه.

$$
\text { وكان لترامب عدة مبررات لإلغاء الاتفاق، وهي: }
$$

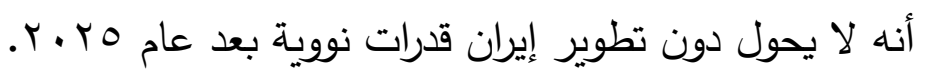




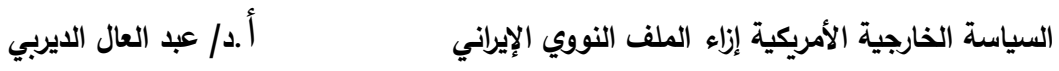

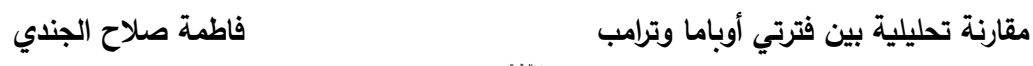

خلوه من بنود تلجم نفوذ إيران في لبنان وسـورية واليمن وتضــع حدًا لبرنامج

$$
\text { الصواريخ البالستية. }
$$

اقترحت فرنســا وألمانيا تضــــين ذلك في اتفاق يلحق بالاتفاق القائم إلا أن ترامب لم

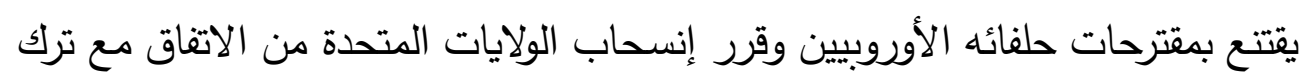

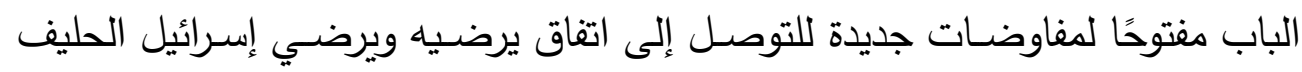

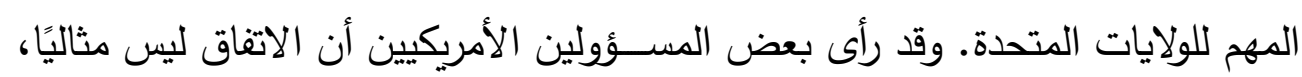

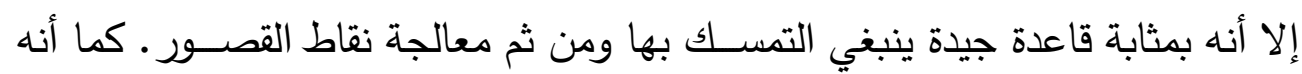

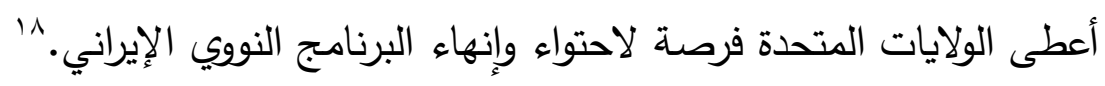




$$
\begin{aligned}
& \text { السياسة الخارجية الأمريكية إزاء الملف النووي الإيراني أد/ عبد العال الديربي }
\end{aligned}
$$

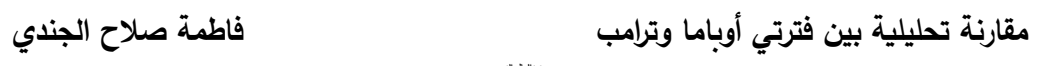

خاتمة الاراسة

تتبنى الولايات المتحدة الأمريكية في سـياستها مع إيران موقفًا معاديًا حيث يعتبر هذا

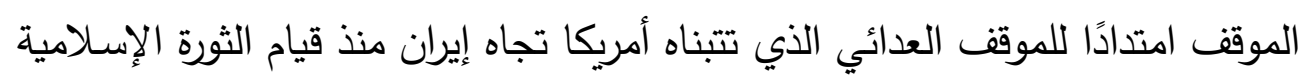

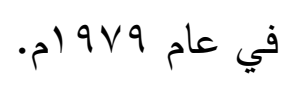

وتتطلق النظرة الأمريكية تجاه الملف النووي الإيراني من حماية المصالح الأمريكية في

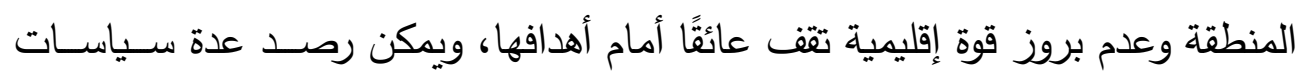
متوالية للموقف الأمريكي تجاه إيران منها:

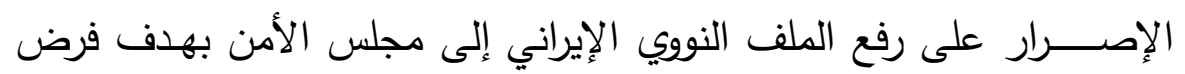

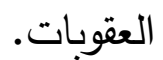
الضغط على الدول التي تقدم التكنولوجيا لإيران مثل روسيا وباكستان.

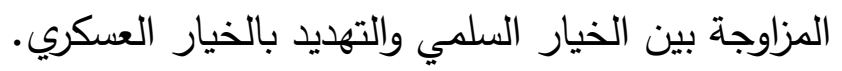

تتعامل الولايات المتحدة مع إيران على أساس أن هدف إيران هو إنتاج السلاح النووي

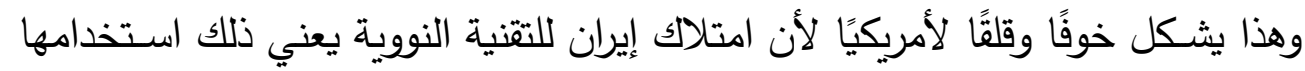




$$
\begin{aligned}
& \text { السياسة الخارجية الأمريكية إزاء الملف النووي الإيراني أد/ عبد العال الديربي }
\end{aligned}
$$

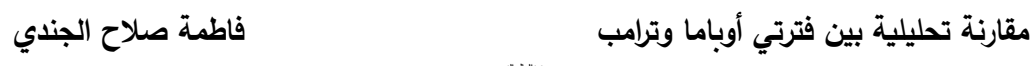

في المجال العســكري مما يؤدي إلى اختلال التوازن في المنطقة والتأثير على الكيان الصهيوني.

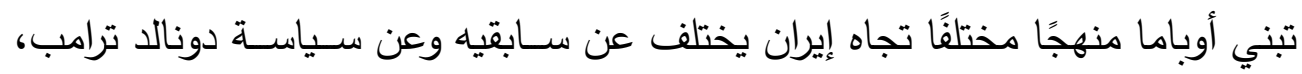

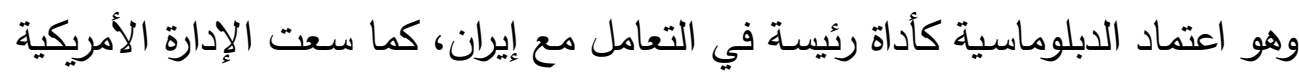

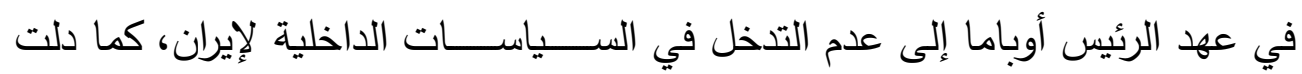

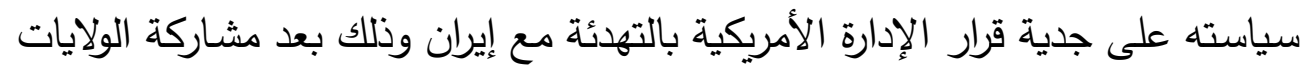

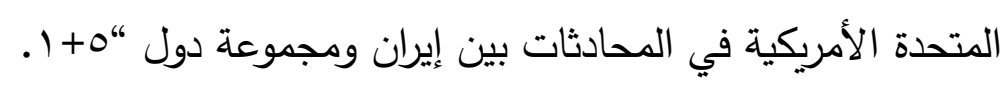




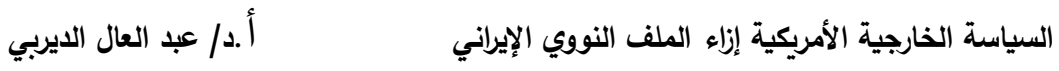

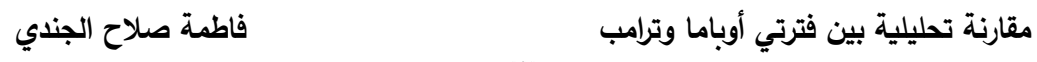

' عبد اللـه فالح المطيـري ، أمن الخليج و التحـدي النـووي الإيراني ، جامعة الثـرق

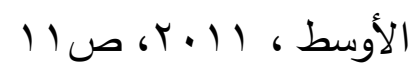

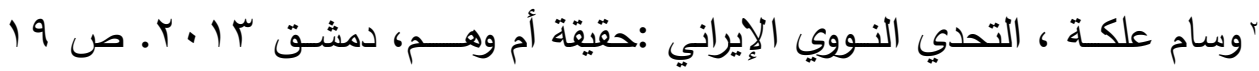
‘ مـركز الدراسات الإستـراتيجية ، البرنـامج النـووي الإيراني (الوقائع و و

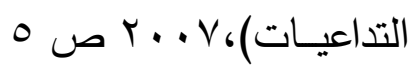

؛ مجلة الأنباء ، النـووي الإيراني :كثف الإزدواجـية الأمـريكية حـول أسلحـة الدمـار

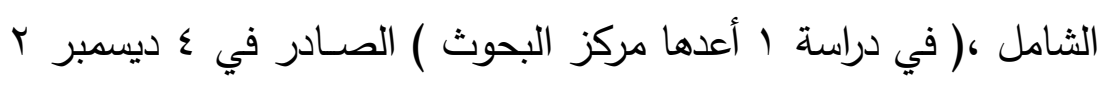
• مرجع سبق ذكره

"جاري سمور ،مواجهة التحدي النووي الإيراني ، سلسلة محاضرات الإمارات مركز الإمارات للبحوث الإستراتيجية ، ج . . T، طبعة الأولى، ص الإيل

" علاء بيومي " بارك اوباما والعالم العربي " سلسلة أوراق الجزيرة، مركز الجزيرة للدراسات، العدد 9، الطبعة الأولى، الدوحة، 1 . . ب. 


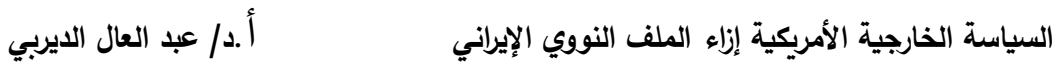

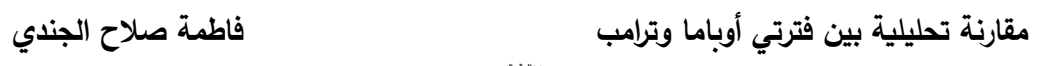

^عبد الله سعد العتيبي، "الأزمة الأمريكية الإيرانية، وانعكاساتها على أمن الخليج العربي"، دوال

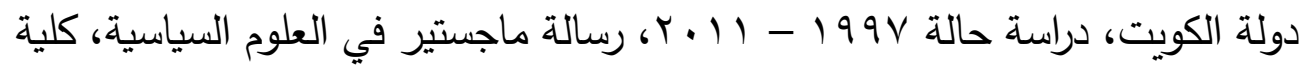

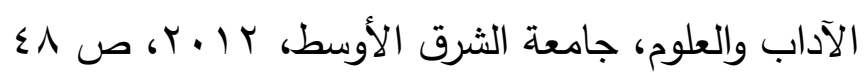

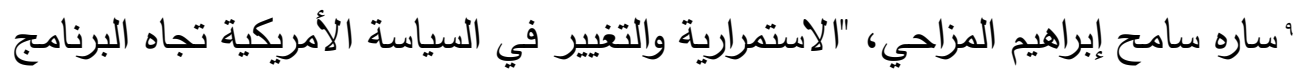

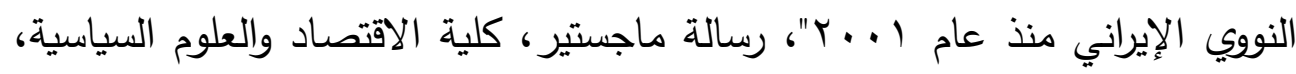

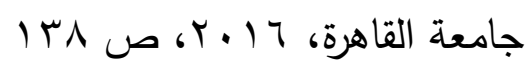
• ايمان ابو زيد مخيمر "البرنامج النووي الإيراني في موازين الاستراتيجية الأمريكية"،

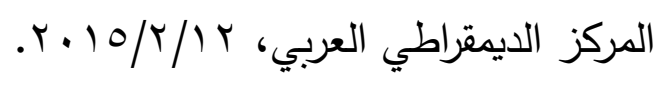

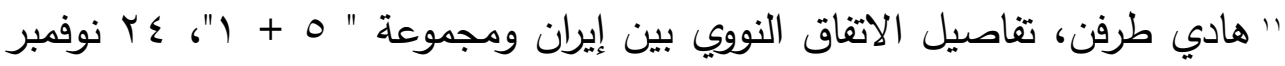

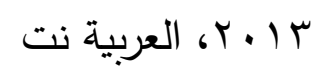
rا المرجع السابق نفسه

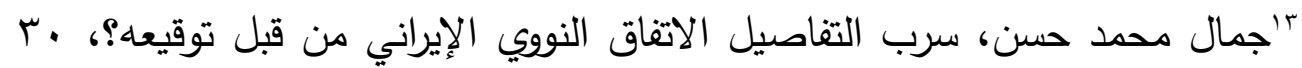

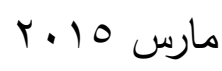




$$
\begin{aligned}
& \text { السياسة الخارجية الأمريكية إزاء الملف النووي الإيراني أد/ عبد العال الديربي }
\end{aligned}
$$

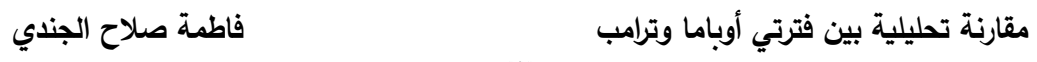

؛'إبراهيم سيف منشاوي، أحمد عبد التواب الخطيب، آفاق السياسة الخارجية الإيرانية

$$
\text { ت الجاه المفاوضات النووية. }
$$

"' قراءة في الاتفاق النووي الإيراني، المركز العربي للأبحاث دراسة السياسات، تقدير موقف، وحدة تحليل السياسات ، 10 يوليو 10 •r.تم زيارة هذه الصفحة في الإيل

$$
r \cdot 1 \wedge / 1 \cdot / r \text {. }
$$

"' علي عدنان محمد حسن، استمرار اميركا في الاتفاق النووي الإيراني على المحك،

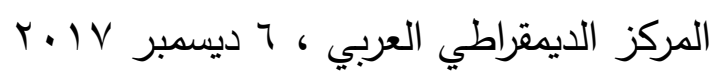
^ا المرجع السابق نفسه 